\title{
Development and Validation of Methodology for the Determination of Residues of Organophosphorus Pesticides in Tomatoes
}

\author{
Anagilda B. Gobo ${ }^{a}$, Márcia H. S. Kurz ${ }^{b}$, Ionara R. Pizzutti ${ }^{b}$, Martha B. Adaime ${ }^{b}$, Renato Zanella ${ }^{*, b}$ \\ ${ }^{a}$ Departamento de Biologia e Química, Universidade Regional do Noroeste do Estado do Rio Grande do Sul, \\ 98700-000 Ijuí - RS, Brazil \\ ${ }^{b}$ Departamnto de Química,Universidade Federal de Santa Maria, 97105-900 Santa Maria - RS, Brazil
}

\begin{abstract}
Os pesticidas organofosforados são freqüentemente aplicados no cultivo de tomate no Brasil. No presente trabalho uma metodologia analítica foi desenvolvida e validada para a quantificação de resíduos dos pesticidas organofosforados acefato, chlorpyrifós, malation, metamidofós and paration metílico em tomate, empregando Cromatografia Gasosa com Detector de Nitrogênio e Fósforo (GCNPD). A possibilidade de ocorrência de efeito matriz foi estudada. As curvas analíticas, preparadas nos extratos da matriz, foram lineares de 0,006 até $0,80 \mathrm{mg} \mathrm{L}^{-1}$. Os estudos de precisão forneceram resultados com $\mathrm{RSD}<15 \%$. As recuperações dos pesticidas, obtidas com as curvas preparadas no extrato da matriz, foram entre 88 e $118 \%$. Com o procedimento proposto foram obtidos limites de quantificação entre 0,0132 e $0,135 \mathrm{mg} \mathrm{kg}^{-1}$.
\end{abstract}

The organophosphorus pesticides are frequently applied in tomato cultivation in Brazil. In the present work an analytical methodology for quantification of the organophosphorus pesticides: acephate, chlorpyrifos, malathion, methamidophos and parathion-methyl residues in tomatoes was developed and validated using Gas Chromatography with a Nitrogen-Phosphorus Detector (GCNPD). The possibility of a matrix effect was studied. Analytical curves prepared in an extract of the matrix were linear from 0.006 to $0.80 \mathrm{mg} \mathrm{L}^{-1}$. The precision studies supplied results with RSD $<15 \%$. The recoveries of the pesticides calculated from the curve prepared in the matrix extract were between 88 and $118 \%$. With the proposed procedure quantification limits between 0.0132 and 0.135 $\mathrm{mg} \mathrm{kg}^{-1}$ were obtained.

Keywords: pesticide residues, organophosphorus, GC-NPD, tomato

\section{Introduction}

The cultivation of tomatoes in Brazil started during the 50's and 60's. Starting from 1972 there was a very large increase in the total production, mainly in the State of São Paulo. ${ }^{1}$ Today, Brazil is one of the world's largest producers of tomatoes, occupying ninth place in the ranking, with a production, in 1997, of 2.6 million tons and median production of $44 \mathrm{tha}^{-1}$. Tomato is a food with an expressive content of vitamins and mineral salts, being considered one of the most important vegetables to be used in human feeding. However, it is a very demanding crop, due to the occurrence of several possible infestations from planting, throughout development and until harvest. ${ }^{2}$ One of the factors that contributes to the high productivity is the

* e-mail: rzanella@base.ufsm.br pesticides use, mainly insecticides and fungicides. Inadequate or incorrect pesticides use, done to control of pests that attack the tomato crop, can represent a serious potential risk to consumer health, because pesticides can leave persistent residues in foods and in the environment. ${ }^{2}$ Thus analysis of pesticide residues is of great importance, because it allows determining if the residues are within the established tolerance limits.

Among the pesticides more used for the control of pests in the cultivation of tomatoes in the Southern area of Brazil, the organophosphorus pesticides, such as: acephate [0,Sdimethyl-phosphoroamidothioate], chlorpyrifos [O,Odiethyl-O-(3,5,6-trichloro-2-pyridylphosphoro-thioate)], malathion [O,O-dimethyl-S-(ethyl-1,2-dicarboethoxy) phosphorodithioate], methamidophos [O,S-dimethylphosphoramidothioate] and parathion-methyl [O,Odimethyl O-(4-nitrophenyl)phosphorothioate], whose chemical structures are presented in Figure 1, stand out. 


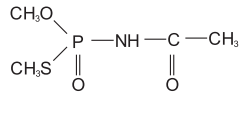

$$
\begin{aligned}
& \text { Acephate }
\end{aligned}
$$

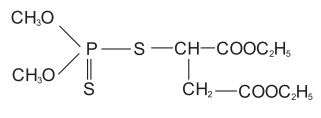

Malathion
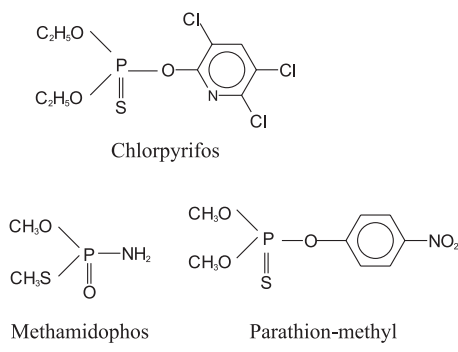

Figure 1. The chemical structures of the organophosphorus pesticides.

The technique most often used for the determination of residues of organophosphorus pesticides in tomatoes is Gas Chromatography (GC) using Nitrogen-Phosphorus (NPD), Flame Photometric (FPD) or Mass Spectrometric (MS) Detectors. The tendency in the analysis of pesticide residues in foods is centered on procedures of multiresidue extraction, thus having a reduction of analysis costs and increased productivity in the laboratories, especially because, for the control of different pests, many different pesticides may be used. In the specific case of the organophosphorus pesticides, the diversities of the physical-chemical properties of the several compounds represent a problem for the development of an analytical methodology using only one extraction procedure.,

For the determination of pesticides in fruits and vegetables several extraction procedures have been used and, in many cases, there is also the need for purification and pre-concentration. ${ }^{3}$ The extraction techniques more used for pesticides in fruits and vegetables are extraction with solvent, supercritical fluid extraction (SFE) and solid phase matrix dispersion (SPMD).$^{4-7}$ In agreement with the literature, one of the solvents more indicated for pesticide extraction in fruits and vegetables is ethyl acetate in the presence of anhydrous sodium sulphate or acetone, followed by partition with dichloromethane and petroleum ether. ${ }^{4,8,9}$

This paper describes the development and validation of a methodology applying extraction with solvent and analysis by GC-NPD for the determination of residues of organophosphorus pesticides used routinely in tomato cultivation. Another propose of the present study was to determine the influence of the matrix in the chromatographic response of organophosphorus pesticides.

\section{Experimental}

\section{Instrumental}

A Varian 3400 gas chromatograph (Palo Alto, USA) with CX 8200 autosampler was used for the gas chromatography, equipped with a splitless 1079 injector at $220^{\circ} \mathrm{C}$, with a glass liner of $0.5 \mathrm{~mm}$ i.d. using an injected volume of $1 \mu \mathrm{L}$; a $30 \mathrm{~m}$ x $0.25 \mathrm{~mm} \times 0.25 \mu \mathrm{m}$ DB-1701 capillary column ( $\mathrm{J} \& \mathrm{~W}$ Scientific, Folsom, USA) and a nitrogen-phosporous detector $\left(300{ }^{\circ} \mathrm{C}\right.$, bead current 3.200 A, flow-rate of the detector gases: make-up (nitrogen) $28 \mathrm{~mL} \mathrm{~min}^{-1}$, hydrogen $5.5 \mathrm{~mL} \mathrm{~min}^{-1}$ and synthetic air $174 \mathrm{~mL} \mathrm{~min}^{-1}$ ). The carrier gas was nitrogen at $1.7 \mathrm{~mL} \mathrm{~min}^{-1}$ and the temperature program of the column oven was $60^{\circ} \mathrm{C}$ ( $3 \mathrm{~min}$ ), $15^{\circ} \mathrm{C} \min ^{-1}$ up to $200{ }^{\circ} \mathrm{C}$, then $3{ }^{\circ} \mathrm{C} \min ^{-1}$ up to $225^{\circ} \mathrm{C}$ (1 min). Data acquisition was through a Star 4.5 Workstation (Varian). A Varian 3800 gas chromatograph (Palo Alto, USA), also equipped with a 1079 injector. All other conditions are the same as used with the Varian 3400.

\section{Reagents, solvents and reference pesticide standards}

All solvents used were of pesticide residue grade from Mallinckrodt, (Phillipsburg, USA). The anhydrous sodium sulfate, analytical grade from Merck (Rio de Janeiro, Brazil), was previously heated at $650{ }^{\circ} \mathrm{C}$ for 4 hours. The sodium chloride, analytical grade, was from Merck (Darmastadt, Germany); the dimethyldichlorosilane was from Sigma-Aldrich Chemie (Steinheim, Germany) and the Extran was from Merck (Rio de Janeiro, Brazil),

The reference pesticide standards of acephate, chlorpyrifos, malathion, methamidophos and parathionmethyl were obtained from Dr. Ehrenstorfer (Augsburg, Germany). The analytical stock solutions of each pesticide were prepared in ethyl acetate and stored in amber flasks maintained at $-18{ }^{\circ} \mathrm{C}$.

\section{Extraction procedure}

The tomato samples were first washed and homogenized in a $2 \mathrm{~L}$ industrial blender. Then $25 \mathrm{~g}$ of sample was weighed into a $250 \mathrm{~mL}$ glass flask with cap and $50 \mathrm{~mL}$ of ethyl acetate and $2.5 \mathrm{~mL}$ of a $10 \%$ solution of sodium chloride were added. The extraction flask was shaked for $25 \mathrm{~min}, 35 \mathrm{~g}$ of sodium sulphate was added and the flask was shaked another $10 \mathrm{~min}$. After standing for $5 \mathrm{~min}$ an aliquot of sample was transferred to an autosampler vial with cap and submitted to analysis.

\section{Validation of the method}

The validation procedure investigated the following parameters: analytical curve and linearity, detection limit and quantification limit, precision (repeatability and intermediate precision) and accuracy. The linearity was studied during the construction of the analytical curves obtained using analytical solutions of the mixture of the 
pesticides prepared in pure solvent and prepared in the extract of the matrix in the concentration range from 0.006 to $0.81 \mathrm{mg} \mathrm{L}^{-1}$. The studies to evaluate the recovery of the pesticides were made in tomato samples without pesticides residues, fortified with an analytical solution containing the pesticides under study, at two different levels. Each concentration level was extracted and analyzed three times. The study of repeatability of the instrument was evaluated with three injections in the chromatographic system for each level of concentration of the analytical solutions in pure solvent and in the extract of the matrix. The intermediate precision tests were carried out in another laboratory, using a Varian 3800 gas chromatograph with the same column. The chromatographic conditions used for this test were similar to those optimized in the development of the proposed method. To determine detection limit (LOD) and quantification limit (LOQ), analytical solutions of the pesticides, prepared in both pure solvent and in the matrix extract, were used. The injections to determine LOD were made in decreasing order of concentration to reach a peak area three times higher in relation to the noise of the baseline at the retention time of the peak of interest. ${ }^{10}$ For the LOQ determination the concentration obtained in the determination of LOD was considered, being multiplied by 3.3 times.

\section{Results and Discussion}

In the optimization of the separation of the pesticides, two capillary columns of different polarities (DB-5 and DB-1701) were tested. The DB-5 column was not considered efficient for the separation of the chlorpyrifos and parathion-methyl, because these peaks elute very close together with most temperature programs. The DB-1701 column was considered more efficient and it was used for the determination of the selected pesticides.
The temperature of the injector and the internal diameter of the silanized glass liner were also evaluated. The best results were obtained with an injector temperature of $220{ }^{\circ} \mathrm{C}$ and with a liner of $0.5 \mathrm{~mm}$ d.i., by virtue of having a reduced contact surface when compared with the one of $2 \mathrm{~mm}$ d.i.. Figure 2 shows a typical chromatogram of a analytical solution of the pesticides methamidophos (0.23 mg L-1), acephate $\left(0.23 \mathrm{mg} \mathrm{L}^{-1}\right)$, chlorpyrifos $(0.049$ mg L $\left.{ }^{-1}\right)$, parathion-methyl $\left(0.099 \mathrm{mg} \mathrm{L}^{-1}\right)$ and malathion $\left(0.029 \mathrm{mg} \mathrm{L}^{-1}\right)$, prepared in an extract of the matrix.

\section{Detection limit and quantification limit}

In agreement with the data presented in the Table 1, it is observed that methamidophos and acephate prepared in pure solvent have LOD and LOQ concentration values higher than the values obtained from the solutions prepared in the extract of the matrix. As already discussed in others papers, ${ }^{5,6}$ these compositions exercise the main effect, because when injected in pure solvent the pesticides undergo larger adsorption in the injection system, while when injected in the extract of the matrix, they undergo the protecting effect of the matrix and a larger amount is transferred to the column. For the other pesticides studied this difference is not too expressive.

Table 1. LOD and LOQ $\left(\mathrm{mg} \mathrm{L}^{-1}\right)$ for the pesticides under study, prepared in pure solvent and in an extract of the matrix

\begin{tabular}{lccccc}
\hline pesticide & \multicolumn{2}{c}{ in pure solvent } & & \multicolumn{2}{c}{$\begin{array}{c}\text { in extract of } \\
\text { the matrix }\end{array}$} \\
\cline { 2 - 3 } \cline { 5 - 6 } & LOD & LOQ & & LOD & LOQ \\
\hline acephate & 0.080 & 0.62 & & 0.0061 & 0.020 \\
chlorpyrifos & 0.0020 & 0.0066 & & 0.00077 & 0.0025 \\
Malathion & 0.0039 & 0.013 & & 0.0020 & 0.0066 \\
methamidophos & 0.080 & 0.33 & & 0.0050 & 0.016 \\
parathion-methyl & 0.0027 & 0.0089 & & 0.0020 & 0.0065 \\
\hline
\end{tabular}

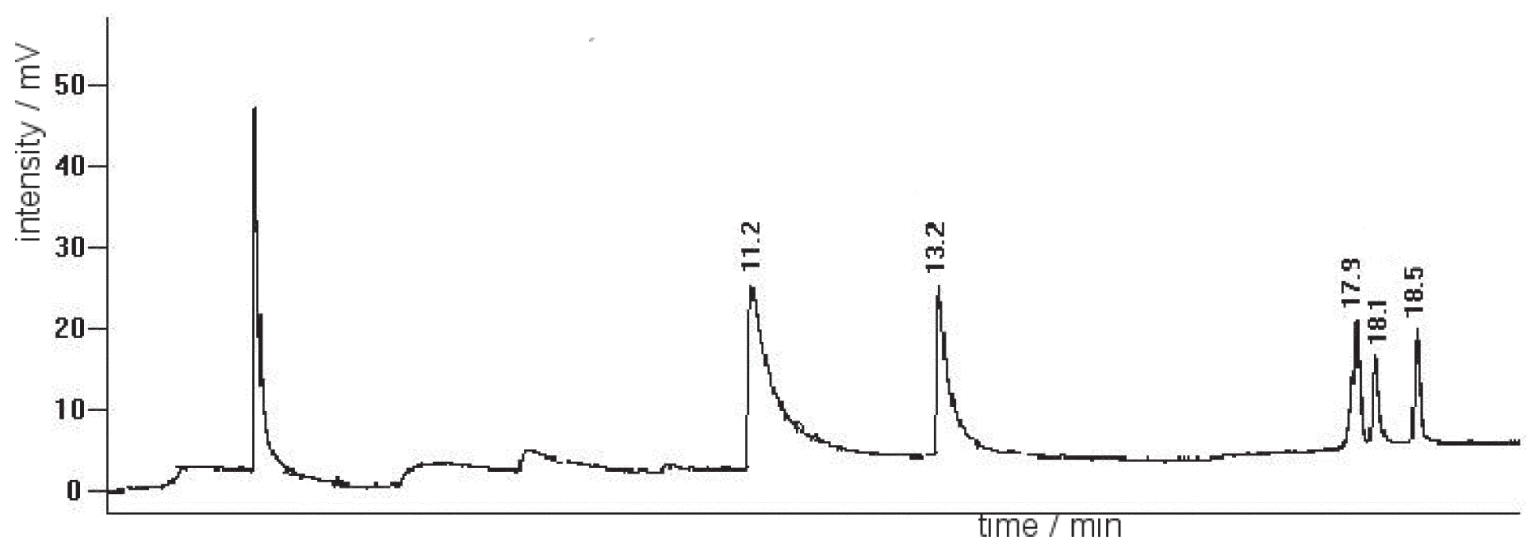

Figure 2. Chromatogram of organophosphorus pesticides prepared in an extract of the matrix: methamidophos $\left(t_{R}=11.2\right.$ min), acephate $\left(t_{R}=\right.$ $13.2 \mathrm{~min})$, chlorpyrifos $\left(t_{R}=17.9\right)$, parathion-methyl $\left(t_{R}=18.1 \mathrm{~min}\right)$ and malathion $\left(t_{R}=18.5\right.$ min $)$. For conditions, see text. 


\section{Analytical curves}

Table 2 presents the results of the analytical curves obtained with the analytical solutions prepared in pure solvent and in solvent containing the matrix extract. From the curves obtained, the model is linear with a determination coefficient $\left(\mathrm{r}^{2}\right)$ for the pesticides greater than 0.99 , considered satisfactory according by the literature, ${ }^{11,12}$ except for methamidophos, which presented an $\mathrm{r}^{2}$ value slightly below 0.98 for the curve prepared in pure solvent. The values obtained for the analytical curves with the solutions prepared in the matrix extract demonstrated satisfactory linearity for the pesticides, except for methamidophos and acephate, for which a percentage above $5 \%$ of the angular coefficient was obtained for some intermediate concentrations. The analytical curves obtained with the solutions in pure ethyl acetate showed satisfactory linearity for chlorpyrifos. For methamidophos, acephate, parathion-methyl and malathion, a percentage above $5 \%$ of the angular coefficient was obtained for most of the concentrations and this can be related to the matrix effect. From the slope of the analytical curves presented in the Table 2 can be concluded that the responses of the NPD for the selected pesticides, when prepared in pure ethyl acetate, are lower, compared with the responses for the pesticides prepared in the matrix extract.
Precision (repeatability and intermediate precision)

Results of precision (Table 3 ) obtained at two concentration levels in the interval of the linear range were considered good, except for methamidophos at the lower level, since they are within the limit accepted for the routine application of a chromatographic method for pesticides, where the precision should be $\pm 15 \% .^{13}$

The tests of intermediate precision of the method, conducted in two different laboratories, were considered satisfactory because they are within the values recommended for precision $(\mathrm{RSD} \pm 15 \%) .{ }^{13}$

\section{Recovery}

For quantification in the recovery studies both analytical curves obtained with the analytical solutions in pure solvent and in the extract of the matrix were used. The results are presented in Table 3 . The recoveries of the pesticides obtained using the analytical curves with the matrix extract are considered satisfactory for all the concentrations studied because they are within acceptable values, as described in the literature for chromatographic methods applied for pesticide residues, which should be between 70 to $120 \%$, with values of RSD being $\pm 20 \% .{ }^{14}$ Using the analytical curves obtained with the pesticides

Table 2. Parameters for the analytical curves obtained for the pesticides prepared in pure solvent and in the matrix extract

\begin{tabular}{|c|c|c|c|c|c|c|}
\hline \multirow[b]{2}{*}{ Pesticide } & \multicolumn{3}{|c|}{ ethyl acetate } & \multicolumn{3}{|c|}{ matrix extract } \\
\hline & linear range $\left(\mathrm{mg} \mathrm{L}^{-1}\right)$ & regressionequation & $\mathrm{r}^{2}$ & linear range $\left(\mathrm{mg} \mathrm{L}^{-1}\right)$ & regressionequation & $\mathrm{r}^{2}$ \\
\hline acephate & $0.080-0.80$ & $y=69464 x-3467$ & 0.9959 & $0.060-0.80$ & $y=160858 x-2899$ & 0.9912 \\
\hline chlorpyrifos & $0.017-0.17$ & $y=99136 x-73$ & 0.9997 & $0.0060-0.086$ & $y=124023 x+58$ & 0.9992 \\
\hline malathion & $0.027-0.32$ & $y=80273 x+186$ & 0.9962 & $0.027-0.30$ & $y=107170 x-259$ & 0.9984 \\
\hline methamidophos & $0.084-0.89$ & $y=40882 x-5033$ & 0.9797 & $0.011-0.81$ & $y=67879 x-626$ & 0.9977 \\
\hline parathion-methyl & $0.027-0.27$ & $y=115799 x-1337$ & 0.9942 & $0.0080-0.13$ & $y=136843 x+171$ & 0.9997 \\
\hline
\end{tabular}

$y=$ peak area; $x=$ pesticide concentration $\left(\mathrm{mg} \mathrm{L}^{-1}\right)$.

Table 3. Recovery values and RSD for two different fortification levels, using the analytical curves prepared with pure solvent and in an extract of the matrix

\begin{tabular}{|c|c|c|c|c|c|}
\hline \multirow[t]{2}{*}{ pesticide } & \multirow{2}{*}{$\begin{array}{l}\text { fortification } \\
\qquad\left(\mathrm{mg} \mathrm{kg}^{-1}\right)\end{array}$} & \multicolumn{2}{|c|}{ from curves in pure solvent } & \multicolumn{2}{|c|}{ from curves in matrix extract } \\
\hline & & recovery $(\%)$ & $\operatorname{RSD}(\%)$ & recovery $(\%)$ & $\operatorname{RSD}(\%)$ \\
\hline \multirow[t]{2}{*}{ acephate } & 0.080 & 250 & 27.0 & 99 & 11.01 \\
\hline & 0.20 & 252 & 21.61 & 118 & 4.37 \\
\hline \multirow[t]{2}{*}{ chlorpyrifos } & 0.010 & 101 & 2.96 & 101 & 11.50 \\
\hline & 0.025 & 125 & 1.80 & 117 & 1.82 \\
\hline \multirow[t]{2}{*}{ malathion } & 0.027 & 87 & 4.46 & 91 & 9.50 \\
\hline & 0.054 & 120 & 4.82 & 93 & 8.22 \\
\hline \multirow[t]{2}{*}{ methamidophos } & 0.076 & 326 & 7.56 & 117 & 20.03 \\
\hline & 0.16 & 206 & 6.19 & 88 & 3.04 \\
\hline \multirow[t]{2}{*}{ parathion-methyl } & 0.027 & 119 & 5.2 & 102 & 3.20 \\
\hline & 0.054 & 89 & 4.69 & 101 & 2.21 \\
\hline
\end{tabular}


prepared in pure solvent the recoveries for methamidophos and acephate were outside the established patterns. Similar results have been described in the literature ${ }^{5,6}$ and they can be attributed to possible systematic errors in the quantification of the pesticides because of the characteristics of the solution in the injection of the samples containing components of the matrix.

\section{Application of the method developed}

The method described here was applied to the analysis of tomatoes sold in various markets in Santa Maria and Ijuí, Rio Grande do Sul State (Brazil), in the period from 23 December 2000 to 26 January 2001 (the summer season). In Brazil, the adopted lowest residue limit (LMR) for tomatoes are: methamidophos, $0.3 \mathrm{mg} \mathrm{kg}^{-1}$, acephate, chlorpyrifos and parathion-methyl, $0.5 \mathrm{mg} \mathrm{kg}^{-1}$, and malathion, $3.0 \mathrm{mg} \mathrm{kg}^{-1} \cdot{ }^{15} \mathrm{Of}$ the eighteen collected samples, just one presented residues $\left(2.4 \mathrm{mg} \mathrm{kg}^{-1}\right)$ of the pesticide methamidophos above the LMR established in Brazil for tomatoes. In the other samples, the residues of the pesticides investigated were below the allowed LMR. Acephate was found in four samples with values between 0.01 and $0.12 \mathrm{mg} \mathrm{kg}^{-1}$.

\section{Conclusions}

The results shown in this work indicate that the method proposed for the simultaneous determination in tomatoes of the six pesticides: acephate, chlorpyrifos, malathion, methamidophos and parathion-methyl, each with different polarities, is simple, fast and efficient. Validation of the proposed method shows satisfactory parameters. The results obtained with the pesticides in pure solvent and with the real matrix extract were compared.

Although several analytical procedures for extraction are described in the literature, this work opted for a methodology using less glassware, to avoid losses due to adsorption of the compounds during the extraction stage. One of the advantages of the procedure is the use of a single solvent during the whole process, which makes the determination faster and less expensive. Selective determination with the NPD does not require purification of the extract, obtaining satisfactory recoveries at concentrations below the maximum concentrations permitted by Brazilian legislation. The heterogeneity of the physical-chemical characteristics of the compounds is unfavorable for the choice of a single adsorbent and does not eliminate the problem completely, while such a cleanup procedure elevates costs and analysis time. One of the more practical alternatives to compensate the matrix effect without elevating the cost of the analyses is to prepare the analytical solutions for quantification in an extract of the matrix. It is also indispensable that all components are properly cleaned and that the GC injector liner is silanized, because the matrix effect depends on the characteristics of the pesticides, matrix type, concentration and cleanliness of the chromatographic system.

The results obtained in the application of the method for the analysis of tomato samples marketed in Southern Brazil indicate the presence of acephate and methamidophos residues. Although these pesticides are highly toxic, they are frequently used for the control of infestations in tomato cultivation. In one of the samples, the level of the residue of methamidophos was well above $\left(2.4 \mathrm{mg} \mathrm{kg}^{-1}\right)$ the maximum limit allowed by the Brazilian legislation $\left(0.3 \mathrm{mg} \mathrm{kg}^{-1}\right)$ for tomatoes. This means that there is not an appropriate level of concern in obeying good agricultural practices on the part of some growers, causing occupational exposure and toxic residues in tomatoes that appear on the market.

\section{Acknowledgements}

Financial support and scholarship from FAPERGS, CAPES and CNPq, Brazil, are gratefully acknowledged. The authors thank Prof ${ }^{a}$. Dr ${ }^{a}$. Carol H. Collins, Unicamp (Brazil) for comments during the preparation of this article.

\section{References}

1. Minami, H.; Haag, H. P.; O Tomateiro, $2^{\text {th }}$ ed., Fundação Cragill: Campinas-SP,1980.

2. Raetano, C. G.; Batista, G. C.; Pesq. Agropec. Bras. 1995, 30, 31.

3. Holstage, D. M.; Scharberg, D. L.; Tor, E. R.; Hart, L. C.; Galey, F. D.; J. Assoc. Off. Anal. Chem. Int. 1994, 77, 1263.

4. Holland, P. T.; Malcolm, C. P. In Emerging Strategies for Pesticide Analysis; Cairns, T.; Sherma, J., eds.; CRC Press: Boca Raton, Florida, 1992, p. 79.

5. Schenck, F. J.; Lehotay, S. J.; J. Chromatogr. A 2000, 868, 51.

6. Erney, D. R.; Poole, C. F.; J. High Resolut. Chromatogr. 1993, 16, 501.

7. Ahamed, F. E.; Trends Anal. Chem. 2001, 20, 649.

8. Torres, C. M.; Picó, Y.; Manes, J.; J. Chromatogr. A. 1996, $754,301$.

9. Hoff, G. R. V. D.; Zoonen, P. V. ; J. Chromatogr. A. 1999, 843, 301.

10. Clifton, E. M.; Pesticides Laboratory Training Manual, AOAC International, Gaithersburg: Maryland, USA, 1996, pp. 7072, 162, 373-375.

11. Juhler, R. K.; J. Chromatogr. A. 1997, 786, 145. 
12. GARP (Associação Grupo de Analistas de Resíduos de Pesticides); Manual de Resíduos de Pesticides em Alimentos, GARP: São Paulo-SP, 1999.

13. Lehotay, S. J.; Eller, K. I.; J. Assoc. Off. Anal. Chem. Int. 1998, 78, 283.

14. Hajslová, J.; Holadová, K.; Kocourek, V.; Poustka, J.; Godula, M.; Cuhra, P.; Kempný, M.; J. Chromatogr. A. 1998, 800, 283.
15. Ministry of Health, Brazil; Relação de Substâncias para uso Fitossanitário e Domissanitário, Portarias do Ministério da Saúde, $2^{\text {nd }}$ ed.; ILSI Brazil: São Paulo, Brazil, 2000, p. 716.

Received: August 13, 2003 Published on the web: November 18, 2004 